\title{
A RELIGIÃO COMO PROJETO EDUCACIONAL EM “ $A$ EDUCAÇÃO DO GÊNERO HUMANO” DE G. E. LESSING
}

\author{
Marcos Fábio A. Nicolau ${ }^{1}$
}

\begin{abstract}
Resumo: O presente texto pretende apresentar a relação entre a filosofia/teologia da história e o ideal de formação da humanidade a partir da religião enquanto uma proposta pedagógica em "A Educação do Gênero Humano" de G. E. Lessing. Ao relacionar analogamente a educação com o processo de revelação ocorrido tanto no indivíduo como no gênero humano, o estudo interpreta a proposta de Lessing enquanto um projeto educacional, o que pode ser demonstrado pela forte influência que o mesmo exerceu sobre o processo de reformas educacionais na Alemanha entre os séculos XVIII e XIX.
\end{abstract}

Palavras-chave: Bildung, Revelação, Filosofia da Educação.

Abstract: This paper aims to present the connection between the Philosophy/Theology of History and the ideal of humankind training from Religion as a pedagogical proposal in "The Education of the Human Race" by G. E. Lessing. By linking the education with the process of revelation occurred both in the individual and in the human race, this study interprets Lessing's proposal as an educational process, which can be demonstrated by the strong influence that it exerted on the Germany process of educational reforms between the eighteenth and nineteenth centuries.

Keywords: Bildung, Revelation, Philosophy of Education.

A formação da humanidade fora um tema de grande relevância no pensamento ocidental dos séculos XVIII-XIX. Votando-nos a realidade alemã, a temática fora debatida a partir de diversas perspectivas, oriundas das reflexões de pedagogos, filósofos, poetas, literatos e cientistas das mais variadas áreas. Em comum tais reflexões tinham a incidência sobre o desafio pedagógico, ou seja, saber qual a melhor forma de formar/educar o homem. Desafio representado na cultura alemã pelo ideal da Bildung ${ }^{2}$,

\footnotetext{
${ }^{1}$ Doutor em Educação pela UFC. Professor Assistente do Curso de Filosofia e Colaborador do Mestrado Profissional em Saúde da Família da Universidade Estadual Vale do Acaraú - UVA/RENASF. Membro do Grupo de Pesquisas em Filosofia da Religião - GEPHIR-UVA/CNPq e do Grupo de Estudo e Pesquisa em Ensino de Filosofia - GEPEFIL/UVA. E-mail: marcosmcj@ yahoo.com.br

${ }^{2}$ Este vocábulo designa uma das figuras históricas determinantes — talvez a última — do que ainda hoje entendemos como cultura, ao lado de $\pi \alpha 1 \delta \varepsilon 1 \alpha$ (paidéia), eruditio e Aufklärung. Em nossa proposta de tese, Bildung expressa, sobretudo, o processo da cultura, da formação pela qual o indivíduo passa, motivo pelo qual adoto a expressão "formação cultural”, conforme a proposta de tradução de Suarez (2005, p. 192).
} 
que impunha a compreensão de que a educação possibilita e capacita o sujeito a conseguir determinar sua vida de forma autônoma, superando as condições de fragmentação as quais estaria suscetível.

Essa proposta, de teor oitocentista, surge assim como algo inseparável de uma profunda vontade de divulgação do saber e da educação das massas, o que faz da época acima mencionada um dos momentos históricos no qual se viveu mais apaixonadamente na Europa esse desafio de formar a humanidade. O que pode ser comprovado, por exemplo, pelo fato de, na Alemanha, surgirem mais escritos e artigos sobre educação e ensino nessa passagem do século XVIII ao XIX, que nos últimos três séculos anteriores juntos (cf. MENZE, 1975, p. 11). Sendo o século XVIII o "século pedagógico" por excelência, não é de se espantar que os grandes poetas alemães, assim como os neohumanistas e os filósofos idealistas do final desse século, tenham se envolvido tão profundamente com a questão da educação. Não sendo por acaso que suas obras tomem forma de verdadeiros tratados sobre educação, constituidores de todo um espaço cultural de cultivo interior, que se tornou o verdadeiro mote de todo o sistema educacional alemão.

Para tal, esses pensadores começaram a atacar o currículo escolar latino, oferecendo uma visão alternativa: queriam que o Estado, e não as igrejas, organizasse as escolas e regulasse os estudos. Como se verá a frente, uma das propostas era a de que as crianças deveriam estudar a língua nacional, bem como a história latina e nacional. $\mathrm{O}$ Estado deveria garantir às crianças o ensino de uma "boa moral", baseada em verdades éticas fundamentais, essencial, na visão desses pensadores, para o bem-estar da sociedade. Finalmente, quiseram fornecer o ensino básico para a população como um todo, mas não chegaram a endossar uma educação universal. Ainda que os governantes não se propusessem, em um primeiro momento, a uma mudança tão radical na esfera educacional, cresce a ideia de que "a instrução pública é um dever da sociedade para com seus cidadãos" (CONDORCET, 2008, p. 17), principalmente no período pósRevolução Francesa.

Não por acaso, justamente na época de 1770 à 1810, quando a Revolução Francesa, as guerras políticas de Napoleão e o emocionalismo naturalista de J.-J. Rousseau $^{3}$ se libertaram da velha ordem social da Europa, completou-se no cenário

\footnotetext{
${ }^{3}$ Os pensadores e pedagogos germânicos dessa época de reformas foram profundamente influenciados por Rousseau, e sua ênfase pela união entre a educação pública, produtora do citoyen, e de uma educação privada, caracterizada pela preservação do homme naturel (cf. HAHN, 1998, p. 3). Nesse sentido, afirma
}

\begin{tabular}{|l|l|l|l|l|}
\hline Qevista Dialectus & Ano 2 & n. 4 & Janeiro-Junho 2014 & p. 28-38 \\
\hline
\end{tabular}


intelectual alemão uma das mais grandiosas épocas da história do espírito germânico. Tais pretensões de consolidar um novo homem influíram diretamente na formação histórico-cultural alemã, que, embora não tenha vivido uma revolução como o vivenciaram ingleses e franceses ${ }^{4}$, assimilaram o ideal iluminista de tal forma, a ser a Prússia reconhecida por Mme. Staël ${ }^{5}$ como o país "dos homens mais espirituais da Europa" (1850, p. 84) - saliente-se que, com uma frequência sem precedentes, teólogos, filósofos, cientistas, enfim, homens de letras, assumiam cargos importantes na administração das escolas, universidades e gabinetes governamentais de educação, que eles mesmos haviam discutido conceitualmente. Que poetas, filósofos e teólogos como F. D. E. Schleiermacher, J. W. von Goethe, J. G. von Herder, J. G. Fichte, G. W. F. Hegel e F. A. Wolf, tenham sido encarregados na direção de ginásios, universidades e mesmo gabinetes governamentais em assuntos educacionais é algo extremamente sintomático dessa nova função social do intelectual no quadro das reformas pedagógicas neo-humanistas e da política alemã que lhe foi contemporânea.

O que é ratificado como um dos princípios gerais da teoria de todas as reformas pensados por Humboldt:

Para efetuar a transição desde a condição atual para a nova que tenha sido acordada, faz-se possível que cada reforma comece com as ideias e pelas cabeças dos homens. (HUMBOLDT, 1983, p. 28)

Portanto, um dos fatores que mais contribuíram para a organização do sistema educacional alemão, são os trabalhos teóricos desses pensadores, dentre os quais sobressai a figura de G. E. Lessing, de que trata o presente texto.

No campo literário, Lessing fora o ícone de uma classe média burguesa germânica em ascensão econômica, porém em uma Alemanha ainda longe de ser

Kant na primeira Crítica: "Apenas Rousseau pode tornar, mesmo o mais ensinado filósofo, um homem honesto e, sem auxílio da religião, pode fazê-lo não considerar a si melhor que o homem comum" (KANT,1989, p. 298).

4 Embora, como nos informa Ringer (2000, p. 15), não devamos exagerar a divergência entre o pensamento anglo-francês e o alemão durante o século XVIII, pois a questão teórica da educação fora também muito importante a oeste do Reno. Para este autor, a peculiaridade da situação social alemã era apenas uma questão de grau, assim como a consequente diferença de orientações intelectuais. Assim não se deve descrever a tradição intelectual alemã apenas em termos de seu desvio de uma suposta norma inglesa empresarial-liberal que rege o mundo Europeu nesse período. O que distinguiu a Alemanha foi exatamente o fato de ter liderado o restante da Europa na criação de um sistema moderno de pesquisa e educação superior, assim como a Inglaterra liderou a Revolução Industrial.

${ }^{5}$ Ao escrever em francês, língua franca daquela época, ela que pessoalmente conhecera Goethe, Schiller, Wieland e August Schlegel, quando em viagem pelo país entre 1803-1804, apresentando-os como "os homens mais instruídos e os mais meditativos da Europa", difundiu as idéias e obras deles por todas as partes. Ainda que sua primeira edição de 1810 fosse interditada pelo regime de Napoleão, em 1814 foi republicado na Inglaterra, de onde ganhou o mundo. Isto fez de Mme. de Staël uma espécie de Tácito de saias.

\begin{tabular}{|l|l|l|l|l|}
\hline Qevista Dialectus & Ano 2 & n. 4 & Janeiro-Junho 2014 & p. 28-38 \\
\hline
\end{tabular}


unificada. Prejudicada por guerras, a realidade alemã não oferecia boas condições de vida para boa parte da população, cujo universo de analfabetos era estimado em cerca de $80 \%$ em meados do século XVIII. ${ }^{6}$ Aliás, é interessante salientar que essa população experimentava também de outra fragmentação, além das política e sócio-econômica: a do ponto de vista linguístico. No século XVIII o idioma alemão, que não era usado em publicações, sequer era adotado nas cortes, salvo quando necessário para se dirigir a subalternos, gente do povo; o francês, assim como toda sua cultura, era a língua eleita inclusive pelo monarca, Frederico II. (cf. OZMENT, 2005, p. 138)

Lessing, seus contemporâneos e, em um sentido figurado, o próprio idioma alemão, tiveram de lutar pelo reconhecimento de sua posição nesse desfavorável contexto. ${ }^{7}$ Sob a égide da Aufklärung, os pensadores alemães defendiam o uso da razão, e, sobretudo, compartilhavam um ideal de homem inspirado no modelo clássico, humanista. Nesse cenário a educação torna-se importante não só para o esclarecimento, mas também para a formação de um público leitor. Assim, a fisionomia espiritual do século XVIII, determinada pela Aufklärung, encontra um ponto culminante na eminente figura de Lessing.

Nessa perspectiva, é interessante compreender que o pensamento lessinguiano está pautado em uma vontade educadora, no sentido de que se esforça por conduzir a humanidade à altura dos ideais da Aufklärung. Por isso, um dos escritos mais peculiares de Lessing é sua A Educação do Gênero Humano (Erziehüng des Menschengeschlechts $)^{8}$, no qual traça uma espécie de esboço da filosofia/teologia da história a modo de educação progressiva da humanidade, através de erros e rodeios.

\footnotetext{
${ }^{6} \mathrm{O}$ número de leitores na Alemanha por volta de 1800 era pouco maior que $1 \%$ da população total, e segundo Jean Paul, escritor da época, o público era constituído por uns 300.000 leitores, algo que se poderia esperar de uma população que em sua maioria vivia no campo e era analfabeta. (cf. BOLLE, 2000, p. 258)

${ }^{7}$ Uma informação relevante já que toda uma geração de intelectuais fora influenciada por essa luta, por exemplo, "Hegel escreveu e lecionou em alemão, no final de um período em que a língua alemã se tornara, nas mãos de Goethe, Schiller, Lessing, etc., o veículo de uma grande literatura nacional, comparada as da França, Inglaterra e Itália, e na qual era usada como nunca antes para expressar ideias científicas, filosóficas e culturais." (INWOOD, 1997, p. 17). Esse movimento de defesa da língua alemão chegou ao ponto de o próprio rei Frederico escrever as memoráveis palavras: "O povo alemão não está desprovido de gênio e intelecto, mas foi dotado por circunstâncias propícias de elevar-se ao mesmo tempo que seus vizinhos. Nós também temos nossos autores clássicos. Todos os lerão, a fim de cultivar a si mesmo através deles. Os nossos vizinhos irão aprender alemão. Será falado com prazer nos tribunais, e pode ser que a nossa língua, quando perfeitamente desenvolvida, se estenda de um extremo ao outro da Europa." (STAHR, 1866, p. 258).

${ }^{8}$ Esse texto apresentado em cem parágrafos, via de regra sucintos, foi publicado em 1780 . No mesmo ano ainda publicou uma continuação de um diálogo de conteúdo crítico diante o Estado e a sociedade, "Ernst e Falk", cuja primeira parte foi editada no ano anterior, o mesmo ano em que levou ao público o drama talvez mais importante dele "Nathan, der Weise", abordando a questão da tolerância, em especial a religiosa. Lessing faleceu em fevereiro do ano 1781.
}

\begin{tabular}{|l|l|l|l|l|}
\hline Qexista Dialectus & Ano 2 & n. 4 & Janeiro-Junho 2014 & p. 28-38 \\
\hline
\end{tabular}


A meu estudo, cabe salientar, interessa o teor mais pedagógico de sua obra e sua influência sobre o cenário educacional alemão, pois se configura como um verdadeiro símbolo do ponto de vista iluminista de educação - mesmo que o próprio autor tenha avisado que "Esse não é lugar de entrar em averiguações sobre o útil que possa ser na pedagogia considerar a educação desde este ponto de vista" (LESSING, 1982, §3, p. 574), creio que não se pode minorizar, ou mesmo desprezar, sua contribuição aos ideais da reforma educacional.

Nesse sentido, dita obra vem a constituir por sua vez uma espécie de filosofia da educação na qual se estabelece um paralelo entre a educação individual e a do gênero humano, como bem expõe em seus primeiros parágrafos:

O que a educação é no homem singular, a revelação é em relação ao gênero humano inteiro.

Educação é a revelação que acontece com o homem singular e revelação é a educação que acontece com o gênero humano e ainda continua acontecendo. (LESSING, 1982, § 1-2, p. 574)

Com isso Lessing quer primeiramente dizer que tanto o indivíduo humano quanto a humanidade na sua totalidade estão sendo submetidos a um processo educacional. A meta do processo educativo viria a consistir para Lessing na constituição de uma verdadeira Humanidade, fundamentada antes de tudo em dois pilares: no desenvolvimento de uma razão autônoma capaz de questionar os dados que maneja e na capacidade do homem para a prática, em todos os seus âmbitos. Lessing identifica a educação com uma revelação que acontece com o indivíduo. Algo se revela para ele. Ainda que possa ser provocada por uma ação exterior, a educação mesma é ratificada aqui como uma atividade interior do indivíduo. Propõe então um ideal de educação que deve melhorar o homem, aperfeiçoá-lo em todas as suas dimensões fundamentais. Do esforço conjunto dos indivíduos resulta o movimento do gênero humano rumo a sua perfeição.

Como bom Aufklärer, Lessing tomará como garantida a autonomia intelectual de cada indivíduo racional, compreendendo o processo pedagógico como mero instrumento:

A Educação não fornece ao ser humano nada que ele não poderia também extrair de si mesmo: ela o fornece aquilo que ele poderia tirar de si mesmo, só que mais rápido e mais fácil. Portanto, a revelação não fornece nada ao gênero humano do qual a razão humana, deixando ela com ela mesma, não poderia descobrir: pois ela deu e está dando a ele as mais importantes daquelas coisas, porém mais cedo. (LESSING, 1982, §4, p. 574)

\begin{tabular}{|l|l|l|l|l|}
\hline Qevista Dialectus & Ano 2 & n. 4 & Janeiro-Junho 2014 & p. 28-38 \\
\hline
\end{tabular}


Interessante notar nessa época a mudança de perspectiva quanto às diferenças postas entre os atos de formar, educar, instruir e disciplinar. Todos são parte do processo de formação cultural (Bildung), mas não são por si mesmos "educação" no sentido lato, buscado pelos iluministas e, posteriormente, pelos neo-humanistas e românticos - o que se verá acentuadamente nas reflexões educacionais de Kant (1999, p. 29-30). Assim, Lessing crê que o ser humano, em princípio, não necessita de orientações, esclarecimentos ou verdades externas a ele - veja-se aqui a influência que as ideias de G. W. Leibniz ainda exerciam no pensamento alemão ${ }^{9}$-, ele mesmo, com suas próprias forças e principalmente com sua própria razão é capaz de adquirir todos os conhecimentos que precisa.

O único problema com o qual se confronta é o do tempo. Aprender sem ajuda externa é plenamente possível, mas leva muito tempo, pois não é fácil. A tarefa da educação, partindo desse pressuposto, só pode ser uma: ajudar a facilitar o caminho. A educação evita uma condenação das futuras gerações a um eterno retorno. O educando pode e deve aproveitar-se das experiências já acumuladas pela humanidade, porém não pode o pedagogo esquecer que todas essas experiências e conhecimentos têm que ser considerados como acessíveis, em princípio, a qualquer ser humano pela própria razão (cf. LESSING, 1982, §26, p. 579). Aligeirar o processo não pode significar dispensar a capacidade do educando de chegar a uma certeza própria sobre os conhecimentos antecipados. Lessing explica tal perigo, ao comparar isso ao

resultado que o professor de aritmética adianta a seus alunos para que de algum modo se orientem por ele em seus cálculos. Porém, se os alunos se contentassem com o resultado adiantado, não aprenderiam a calcular nunca e fariam mau uso do propósito com o qual o bom mestre lhes deu uma pista para seu trabalho. (LESSING, 1982, § 76, p. 590)

\footnotetext{
${ }^{9} \mathrm{Na}$ metafísica leibniziana, as mônadas - enquanto substâncias simples - são os verdadeiros átomos da natureza, e, em uma palavra, os elementos das coisas. Para Leibniz, uma mônada jamais poderá ser alterada ou modificada em seu íntimo por outra criatura qualquer, pois as mônadas são intransponíveis. Nem se pode conceber nela - dirá Leibniz - algum movimento interno que, de fora, seja excitado, dirigido, aumentado, ou diminuído lá dentro, como acontece nos compostos, onde ocorrem mudanças entre as partes. As mônadas não têm "janelas" por onde qualquer coisa possa entrar ou sair (não existe interação, uma mônada não influi sobre a outra): "Não há meio também de explicar como a Mônada possa ser alterada ou modificada em seu íntimo por outra criatura qualquer, pois nada se lhe pode transpor, nem se pode conceber nela algum movimento interno que, de fora, seja excitado, dirigido, aumentado ou diminuído lá dentro, como nos compostos, onde há mudança entre as partes. As Mônadas não têm janelas por onde qualquer coisa possa entrar ou sair" (LEIBNIZ, 1974, §7, p. 63). - A Monadologia de Leibniz fora escrita em originalmente em francês, em 1714, sendo disponibilizada em 1720 em sua versão alemã por H. Köhler, tendo um profundo efeito sobre o século XVIII alemão, principalmente sobre Lessing e Goethe (cf. MARTISON, 2005, p. 47).
}

\begin{tabular}{|l|l|l|l|l|}
\hline Qexista Dialectus & Ano 2 & n. 4 & Janeiro-Junho 2014 & p. 28-38 \\
\hline
\end{tabular}


Esse princípio, para Lessing, é tanto verdadeiro para o processo da educação individual quanto para o do gênero humano. Por isso, refletirá sobre esse tempo interior na educação:

E assim, como para a Educação não é aleatório em que seqüência desenvolvem-se as forças do homem, de forma que ela não pode ensinar tudo de uma vez, igualmente Deus na sua revelação tinha que seguir uma determinada ordem, uma determinada medida. (LESSING, 1982, § 5, p. 574)

Por isso, ao comparar o desenvolvimento do gênero ao do indivíduo, Lessing encontrará essa didática divina na escolha do povo de Israel, que assim como uma criança teria que ser educado "mediante castigos e prêmios sensíveis e imediatos" (LESSING, 1982, §16, p. 576). Para Lessing, a história da religião era um relato da educação espiritual do homem. As religiões históricas são outras tantas etapas desse processo educativo da humanidade. O Antigo Testamento conduziu o povo de Israel à adoração de um só Deus muito antes que fosse capaz de entendê-lo racionalmente (cf. HOGDSON, 1999, p. 39-40). Com sua visão de uma vida ultraterrena, o Novo Testamento tem educado os homens na simplicidade de sentimentos, o que caracterizaria uma nova fase no desenvolvimento, ou aperfeiçoamento, do gênero humano. É a revelação gradual de Deus aos homens, revelação que para todo o conjunto do gênero humano corresponde ao que é a educação para o indivíduo.

A analogia entre a formação do gênero e a do indivíduo é significativa, pois marca uma das características gerais da Aufklärung: o interesse pela educação da humanidade. Em meio a essa proposta germânico-iluminista, a convergência existente entre revelação e educação para Lessing demonstraria uma pedagogia divina no sentido de respeitar o tempo de aprendizagem do homem. Pois, não se pode dizer com certeza, no conjunto das múltiplas dimensões do ser humano, qual é o caminho mais curto para esse ou aquele educando. A paciência pedagógica no todo se comprova na situação educacional concreta. E isso principalmente em um aspecto: o da paciência em relação ao estado de desenvolvimento humano em que o indivíduo se encontra. ${ }^{10}$ Seguindo o pensamento de Lessing teríamos que nos perguntar em relação a cada educando se ele se encontra ainda numa fase em que somente faz o bem por causa das consequências imediatas que esse ato traz consigo, ou seja, recompensa ao fazê-lo e punição ao fazer o seu contrário. O que expõe logo à frente:

\footnotetext{
10 "Não se trata de ganhar tempo, mas de perdê-lo", essa postura, encontrada no Livro II do Emílio, será a maior e mais importante regra da educação, segundo o nobre cidadão de Genebra. Essa regra somente poderia ser desconsiderada "Se as crianças saltassem de uma vez das tetas para a idade da razão" (ROUSSEAU, 1999, p. 91).
}

\begin{tabular}{|l|l|l|l|l|}
\hline Qevista Dialectus & Ano 2 & n. 4 & Janeiro-Junho 2014 & p. 28-38 \\
\hline
\end{tabular}


Revelar-lhe já agora estas coisas, as quais tão pouco avisada estava sua razão, que outra coisa haveria sido, senão a incorrência de Deus no defeito do apressado pedagogo que prefere fazer adiantar à criança e vangloriar-se disso, em lugar de dar-lhe um sólido ensino? (LESSING, 1982, §17, p. 576-577)

Dotar de boas bases o educando deve ser o mais importante procedimento do pedagogo, em vias de seu sólido ensino, fruto de um caminho percorrido "a passos lentos, porém seguros" (LESSING, 1982, §21, p. 577), motivo pelo qual lhe é permitido "saltar algum outro ponto importante da ciência ou da arte que venha expor", caso note que tal ponto não está ainda ao alcance da capacidade do educando. Nesse momento, Lessing reflete sobre os livros elementares, ou seja, os livros escolhidos pelo pedagogo para estimular o educando, que tem como função deixar aberto ao mesmo "todos os acessos" aos conhecimentos que propõe expor. No decorrer de tal reflexão, Lessing irá impor limites ao uso desses livros, apresentando um paralelo desse tipo de livro, dito elementar, e as revelações bíblicas (Antigo e Novo Testamento), que devem, por uma natural lógica pedagógica, ser ultrapassados em algum momento pelo gênero humano.

Cabe salientar que em Lessing a razão, além da dimensão epistemológica, também abrange o estético e principalmente o ético, procedimento que se tornará padrão no modo de pensar alemão (cf. BEISER, 2009, p. 261-262). Não se trata, ao mesmo tempo, de um conceito teórico, de belas abstrações teóricas sem repercussão e confirmação na vida prática. Lessing abominava os pensamentos que serviam para satisfazer os anseios teóricos sem consequências no agir humano. Não abria mão da necessidade de coerência entre teoria e prática (cf. MARTISON, 2005, p. 58). O que fora muito bem exposto por H. Arendt:

\footnotetext{
Para Lessing, o pensamento não brota do indivíduo e não é a manifestação de um eu. Antes, o indivíduo - que Lessing diria criado para a ação, não para o raciocínio - escolhe tal pensamento porque descobre no pensar um outro modo de se mover em liberdade no mundo. De todas as liberdades específicas que podem ocorrer em nossas mentes quando ouvimos a palavra "liberdade", a liberdade de movimento é historicamente a mais antiga e também a mais elementar. Sermos capazes de partir para onde quisermos é o sinal prototípico de sermos livres, assim como a limitação da liberdade de movimento, desde tempos imemoriais, tem sido a pré-condição da escravização. A liberdade de movimento é também a condição indispensável para a ação, e é na ação que os homens primeiramente experimentam a liberdade no mundo. (ARENDT, 2008, p. 16)
}

O agir pedagógico, nesse caso, teria a característica de um controle externo, prático, que mantém o educando via recompensa e repressão no caminho do bem. Essa pedagogia dos primeiros passos perderia seu sentido no momento em que o educando começa a fazer o bem, visando metas a médio e longo prazo. A tarefa pedagógica nesse

\begin{tabular}{|l|l|l|l|l|}
\hline Qexista Dialectus & Ano 2 & n. 4 & Janeiro-Junho 2014 & p. 28-38 \\
\hline
\end{tabular}


caso seria fazer a recompensa no futuro tão estimulante e motivadora para o educando, que as punições e represálias se tornem sempre mais desnecessárias. O estado mais maduro em termos de humanidade se alcança, quando as próprias promessas se tornam dispensáveis, quando o educando encontra o sentido da própria ação no bem em si mesmo. Ele faz o bem porque encontra o sentido da sua vida nisso. Se essa atitude se consolidou, o processo de educação chegou ao seu fim. Tal otiminismo teleológico está presente nas palavras de Lessing:

\begin{abstract}
Ou será que o gênero humano não chegará nunca aos mais altos graus da ilustração e a pureza? Nunca?

Nunca? Longe de mim pensar semelhante blasfêmia, Deus bondosíssimo! - A educação tem sua meta, tanto a educação do gênero humano como a do indivíduo. O que se educa, para algo se educa. [...]

Aponta a isso a educação humana e não vai chegar até aí a educação divina? $O$ que consegue a arte com o indivíduo, não vai consegui-lo a Natureza com a totalidade? Blasfêmia, blasfêmia!

Não, não; chegará, seguro que chegará o tempo do cumprimento, quando o homem, a medida que sua inteligência se vá convencendo de que o futuro será cada vez melhor, não tenha já necessidade de obter desse mesmo futuro motivos para suas ações; o tempo no qual o homem fará o bem porque é o bem e não porque se estabeleçam prêmios arbitrários com o fim propriamente de fixar e robustecer seu volúvel olhar para que saiba ver os prêmios interiores do bem, que são melhores. (LESSING, 1982, §81-82 e §84-85, p. 591-592)
\end{abstract}

A educação tem sua meta. A vontade educadora que perpassa a obra de Lessing, como dito acima, tem aqui seu ápice. $O$ que se educa para algo se educa. A crença oitocentista alemã de supremacia da razão humana encontra aqui seu mote, cabe ao processo educacional a função divina de conduzir o indivíduo a tal meta, assim como Deus, desde os primórdios, conduz seu povo, ou melhor, o gênero humano. O bem, a verdade, o esclarecimento são a meta, a realização, a perfeição humana, que devem sempre ser fim desse processo que é a educação.

Porém, cabe ressaltar, para Lessing não é a posse da verdade, ou mesmo do bem, senão o esforço para alcançá-la ${ }^{11}$, o que determina o valor do homem, ou seja, seu aperfeiçoamento, princípio que irá guiar as posteriores reflexões pedagógicas germânicas aplicadas ao sistema educacional. Por isso, outro tema central do pensamento de Lessing é o problema da relação entre o esforço para a verdade e a verdade mesma, entre a história e o eterno, entre as conquistas parciais e limitadas que o

\footnotetext{
${ }^{11}$ Diz Arendt (2008, p. 17): "seu pensar não era uma busca da verdade, visto que toda verdade que resulta de um processo de pensamento necessariamente põe um fim ao movimento do pensar. Os fermenta cognitionis que Lessing disseminou pelo mundo não pretendiam comunicar conclusões, mas estimular outras pessoas ao pensamento independente, e isso sem nenhum outro propósito senão o de suscitar um discurso entre pensadores."
}

\begin{tabular}{|l|l|l|l|l|}
\hline Qexista Dialectus & Ano 2 & n. 4 & Janeiro-Junho 2014 & p. 28-38 \\
\hline
\end{tabular}


homem consegue no tempo e a verdade absoluta. Eis o famoso trecho, no qual Lessing expõe a busca e não posse como o essencial da condição humana:

\begin{abstract}
O valor do homem não reside na verdade que se possui ou pretende possuir, mas no esforço sincero que se põe em alcançá-la. Porque as forças que aumentam a perfectibilidade humana não crescem pela posse, mas pela busca da verdade. Se Deus, guardando na mão direita toda a verdade e não tendo na esquerda senão o desejo sempre ardente da verdade, me dissesse: "Escolhe!", mesmo correndo o risco de me enganar para sempre e pela eternidade, eu me inclinaria humildemente para sua mão esquerda e diria: "Pai, dê-me esta mão; a verdade absoluta pertence somente a ti. (LESSING, 1979, p. 32-33)
\end{abstract}

Com Lessing as bases foram estabelecidas, surgia um modelo de formação cultural (Bildung), no qual poderiam guiar-se as instituições escolares na busca de um ideal de humanidade para o povo alemão.

\title{
Referências Bibliográficas
}

ARENDT, H. Homens em tempos sombrios. Tradução de Denise Bottmann. São Paulo: Cia. Das Letras, 2008.

BEISER, F. C. Diotima's children: German aesthetic rationalism from Leibniz to Lessing. Oxford: Oxford University Press, 2009.

BOLLE, Willi. Fisiognomia da metrópole moderna: representação da história em Walter Benjamin. $2^{\mathrm{a}}$ Ed. São Paulo: Edusp, 2000.

CONDORCET, J.-A.-N. de Caritat, marquês de. Cinco memórias sobre a educação pública. Tradução de Maria das Graças de Souza. São Paulo: Editora da Unesp, 2008.

MARTINSON, S. D. Lessing and the European Enlightenment. In: FISCHER, B.; FOX, T. C. (Eds.). A Companion to the works of Gotthold Ephraim Lessing. Nova Iorque: Camden House, p. 41-63, 2005.

HODGSON, P. C. God's wisdom: Toward a theology of education. Louisville: Westminster John Knox Press, 1999.

HUMBOLDT, W. von. Selección de escritos político-filosóficos de Wilhelm von Humboldt. Introducción, selección y traducción de Joaquín Barceló. In: Estudios Públicos, $\quad \mathrm{n}^{\mathrm{0}} \quad 12,1983.10 \mathrm{Disponível}$ em http://www.cepchile.cl/dms/lang_1/cat_623_inicio.html. Acessado em 08 de maio de 2014.

KANT, I. Crítica da Razão Pura. Tradução de Manuela P. dos Santos e Alexandre F. Morujão. Lisboa: Fundação Calouste Gulbenkian, 1989.

Unimep, 1999.

Sobre a pedagogia. Tradução de Francisco C. Fontanella. Piracicaba:

\begin{tabular}{|l|l|l|l|l|} 
Qevista 2 ialectus & Ano 2 & n. 4 & Janeiro-Junho 2014 & p. 28-38
\end{tabular}


LEIBNIZ, G. W. Monadologia. Tradução de S. Marilena Chauí. São Paulo: Abril Cultural, 1974 (Coleção Os Pensadores).

LESSING, G. E. La Educacion del Genero Humano. In: . Escritos filosóficos y teológicos. Tradução de Augustin Andreu Rodrigo. Madrid: Editora nacional, p. 573603, 1982.

Eine Duplik. In: Lessings Werke in einem Band, Tomo 8. München: Verlag das Bergland-Buch, 1979, apud HADOT, P. O véu de Isis - Ensaios sobre a história da ideia de natureza. São Paulo: Edições Loyola, 2006.

MENZE, C. Die Bildungsreform Wilhelm Von Humboldt. Hannover: Schroedel, 1975.

OZMENT, S. Una Fortaleza Poderosa: Historia del pueblo alemán. Barcelona: Crítica, 2005.

RINGER, F. K. O declínio dos mandarins alemães: a comunidade acadêmica alemã, 1890-1933. Tradução de Dinah de Abreu Azevedo. São Paulo: Edusp, 2000.

ROUSSEAU, J.-J. Emílio ou Da Educação. Tradução de Roberto Leal Ferreira. São Paulo: Martins Fontes, 1999.

STÄEL, Mme. De L’Allemagne. Paris: Librarie de Firmin Didot Freres, 1850.

STAHR, A. The life and works of Gotthold Ephraim Lessing - Vol. I. Tradução de E. P. Evans. Boston: William V. Spencer, 1866.

SUAREZ, R. Nota sobre o conceito de Bildung. In: Kriterion: Revista de Filosofia, v. 46, n. 112, Belo Horizonte, p. 191-198, Dezembro de 2005.

\begin{tabular}{|l|l|l|l|l|}
\hline Qevista Dialectus & Ano 2 & n. 4 & Janeiro-Junho 2014 & p. 28-38 \\
\hline
\end{tabular}

